\title{
Impact of Deficient Nutrition on Health Condition of Persons with Dementia
}

\author{
Velija Katica $^{1}$, Nadžida Mlaćo ${ }^{2}$, Amela Katica ${ }^{2}$ and Jasmin Katica ${ }^{3}$ \\ 1. Department of Animal Science, Veterinary Faculty, University of Sarajevo, Zmaja od Bosne 90, 71000 Sarajevo, Bosnia and \\ Herzegovina \\ 2. Department of Anatomy and Histology with Embryology, Veterinary Faculty, University of Sarajevo, Zmaja od Bosne 90,71000 \\ Sarajevo, Bosnia and Herzegovina \\ 3. Department of Feed and Nutrition of Domestic Animals, Veterinary Faculty, University of Sarajevo, Zmaja od Bosne 90, 71000 \\ Sarajevo, Bosnia and Herzegovia
}

\begin{abstract}
Dementia is a loss of mental ability (ability to think, remember and make logical conclusions) which, in principle affects normal everyday life of a person. Dementia is not a disease but a group of symptoms that may cause different diseases. Symptoms include change of behaviour, character and unexpected changes in the mood. Poor quality of nutrition affects significantly the intensity of dementia. Balanced diet that meets healthy safety standards and requirements will satisfy the needs of an organism for vitamins and minerals and special attention should be given to intake of folic acid, vitamin B12 and minerals zinc and selenium. Intake of omega3 fatty acids is a source of fuel for blood vessels, particularly for the ones of the nervous tissues.
\end{abstract}

Key words: Dementio, nutrition, war period.

\section{Introduction}

\subsection{Importance of Proper Diet for Disease Prevention}

The main role of nutrition is to sustain an organism of a human being who expends every day through releasing energy and constantly performing some of the life important functions.

Food needs to consist of many diverse nutrients that an organism uses to create parts of morphological structures to perform the actions that are important for life. As a consequence of these processes, energy is released in the body.

Nutrition maintains the normal functioning of the body's organs providing at the same time the substances necessary for growth of a body that is being developed and expended.

The substances that are most important for the development are proteins, fats and carbohydrates, the

Corresponding author: Velija Katica, Ph.D., main research fields: food, animal science and nutrition. main ingredients of food and energy carriers. Aging and other insults affect the brain. Reduction of brain tissue is not always proportional to the reduced functionality of the nervous tissue. The remaining cells intensify their metabolism, and proteins play a special role in the metabolism of the nervous cells and therefore compensate for the lack in the function of degenerated cells.

Slowdown of electric activity in the brain is attributed to the nervous cells (Fig. 1).

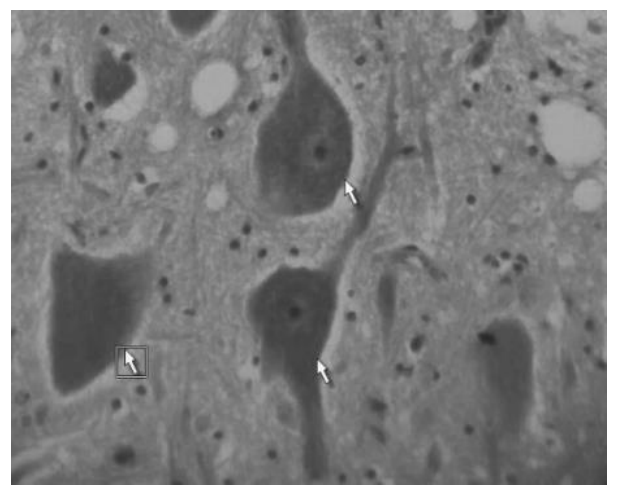

Fig. 1 Multi-polar nervous cells; HxE × 400 . 
However, the studies show that nervous cells do not degenerate, i.e. there is no slowdown of electric activity (transmission of nervous stimuli) if there is physical, spiritual and mental activity and proper diet and continuous brain activity [1].

Besides these substances, food must contain vitamins, minerals and water.

Consequences of deficient nutrition may manifest as primary or secondary diseases.

Diseases of insufficient nutrition may be the consequence of insufficient intake of some nutriments with food (primary diseases) or insufficient nutrition (primarily starvation).

Secondary diseases of insufficient nutrition emerge because of different illnesses of gastrointestinal tract, liver and pancreas, followed with digestion and nutriment absorption disorders.

\section{Results and Discussion}

\subsection{Carbohydrates and Fats}

The group 1 are diseases that come as consequences of insufficient or excessive intake of high-energy nutrients (carbohydrates and fats). Insufficient intake of energy nutrients results in faster or slower weight loss - thinness (malnutrition). Insufficient intake of important (essential) amino acids brings to protein malnutrition. Finally, insufficient intake of essential (important) fatty acids causes fat malnutrition. The opposite is excessive intake of energy substances and nutrients (carbohydrates and fats) that will manifest in a gradual weight increase, i.e. obesity.

\subsection{Vitamins}

The group 2 diseases associated with improper nutrition emerge as consequences of insufficient or incomplete intake of vitamins (hypovitaminosis and avitaminosis) or excessive deposits of vitamins (hypervitaminosis).

Hypervitaminosis emerges because of excessive intake of liposoluble vitamins as their excretion from the organism is difficult. Excessive intake of hydro soluble vitamins does not manifest in hypervitaminosis as they excrete very easily into external environment.

\subsection{Water and Mineral Substances}

The last group of diseases associated with improper nutrition belong to the diseases that emerge amid insufficient or excessive intake of water and mineral substances.

For example, hyposidermic anaemia due to insufficient intake of iron, hypothyroidism due to insufficient intake of iodine, cavities amid insufficient intake of fluoride, osteoporosis after menopause and andropause, etc..

\subsection{Daily Mail of Population of RBiH during the} Period 1992-1995

In the overall energy intake of an average daily meal used in the nutrition of the RBiH (Republic of Bosnia and Herzegovina) population during the 1992-1995 period, a relative share of fat was at 43.00 g or $19.00 \%$ - severe deficit, carbohydrates at 347.50 $\mathrm{g}$ or $67.00 \%$, which is in excess and proteins $63.00 \mathrm{~g}$ or $14.00 \%$, which is within international normative (Fig. 2).

These are the values defined on the basis of the results of laboratory testing of the share of different nutrients in the total energy intake of a daily meal and not the results of real needs for nutrients in a daily meal of the $\mathrm{RBiH}$ population during the mentioned period (Fig. 3).

\subsection{Hygienic Standards of Food}

Total $4 \%$ of food items used in nutrition of the $\mathrm{RBiH}$ population was examined.

Ninety two percent refers to organoleptic examinations, only $8 \%$ refer to microbiological, chemical, radiological and toxicological examinations. The analysis included all food items that showed signification deviations in the fundamental organoleptic properties (colour, scent, taste and consistence). Most 


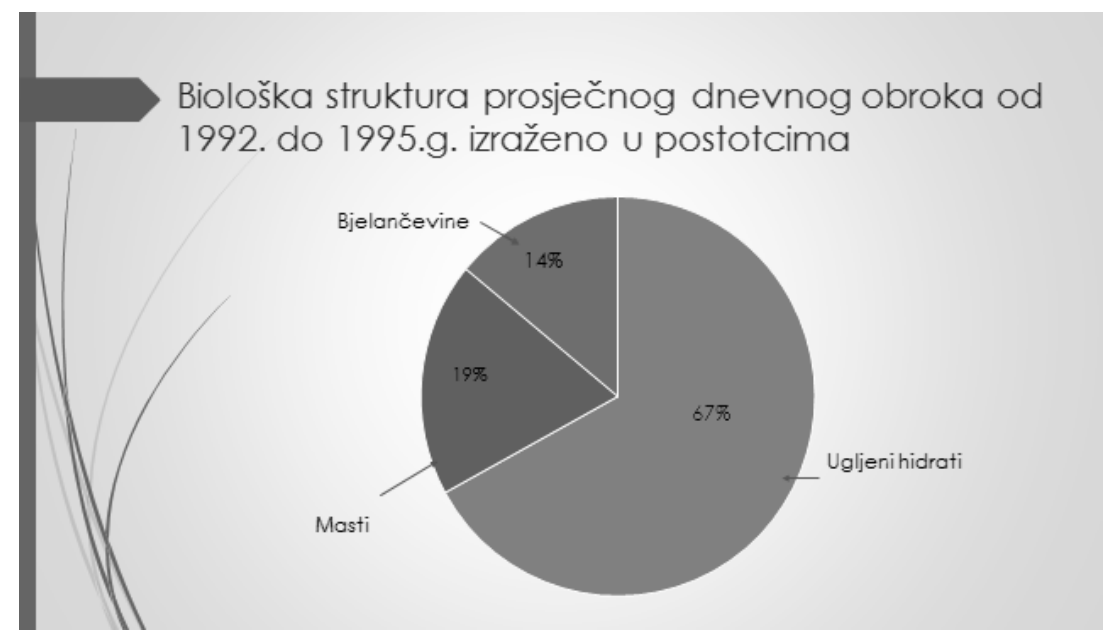

Fig. 2 Biological structure of an average daily meal during the 1992-1995 period.

\begin{tabular}{|c|c|c|c|c|c|c|c|}
\hline \multirow[t]{2}{*}{ Godina } & \multicolumn{2}{|c|}{ Bjelačevine } & \multicolumn{2}{|c|}{ Masti } & \multicolumn{2}{|c|}{ Ugljeni hidrati } & \multirow{2}{*}{ Ev kJ } \\
\hline & $g$ & $\%$ ev & $g$ & $\%$ ev & $g$ & $\%$ ev & \\
\hline 1992.g. & 68,00 & 12 & 47,50 & 18 & 430,00 & 70 & 10.095 \\
\hline 1993.g. & 69.50 & 14 & 36,00 & 16 & 360,00 & 70 & 8.772 \\
\hline 1994.g. & 52,00 & 17 & 22,50 & 16 & 210,00 & 67 & 5.372 \\
\hline 1995.g. & 71,00 & 12 & 66,50 & 26 & 390,00 & 62 & 9.955 \\
\hline $\begin{array}{l}\text { Prosječno } \\
1992 .-1995 .\end{array}$ & 63.00 & 14 & 43,00 & 19 & 347,50 & 67 & 8.549 \\
\hline
\end{tabular}

Fig. 3 Biological structure and energy values (ev) of average daily meal of population of RBIH during the 1992-1995 period.

frequently they did not have the prescribed declaration or the declaration was not translated into Bosnian language. The results were affected by inadequate storage, transport, processing facilities, preparation and distribution of food and a severe lack of laboratory equipment and chemicals necessary for testing the food samples.

In the regulation on microbiological conditions for foodstuffs in the distribution, $17.48 \%$ of food samples did not meet the criteria. Food samples that did not meet the hygienic safety standards contained unallowable presence of Proteus spp. 34.16\%, Sulphide reducing clostridia 20.81\%, Staphilococcea spp. $20.19 \%$, E. coli $17.08 \%$ and an increased total number of microorganisms 7.76 (Figs. 4-7).
2.6 Foodstuffs of Plant Origin that do not Meet Food Safety Standards

Most frequently, the following foodstuffs were included: wheat flour, soy, rice, marmalade, biscuits, oil, dehydrated pees, etc. (Figs. 8, 10-12).

Sulphide reducing clostridia and elevated percentage of moisture were isolated in some samples of wheat. Biscuits Handle with Care-humanitarian aid for children and elderly from the UNICEF (United Nations International Children's Emergency Fund) programme with unknown countries of origin and most likely the war reserves considering the years of production (1957-1960) [2, 3]. The laboratory testing found increased overall numbers of microorganisms and increased presence of anaerobic bacteria (Fig. 9). 
Fig. 4 Canned food donated over the course of the mentioned period.

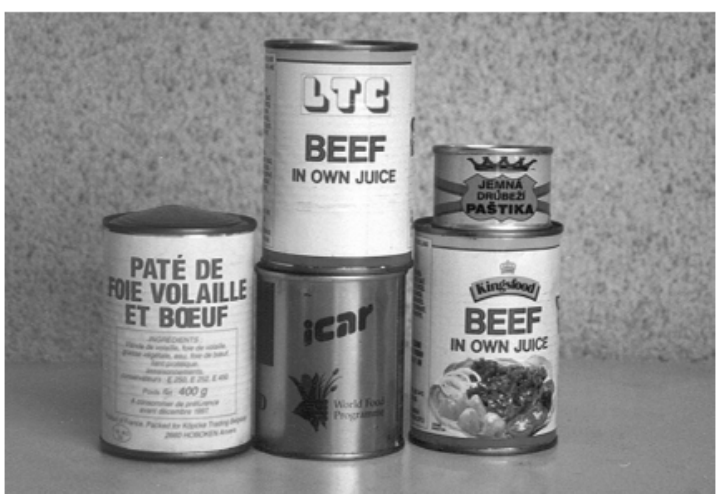

Fig. 5 Canned food donated over the course of the mentioned period.

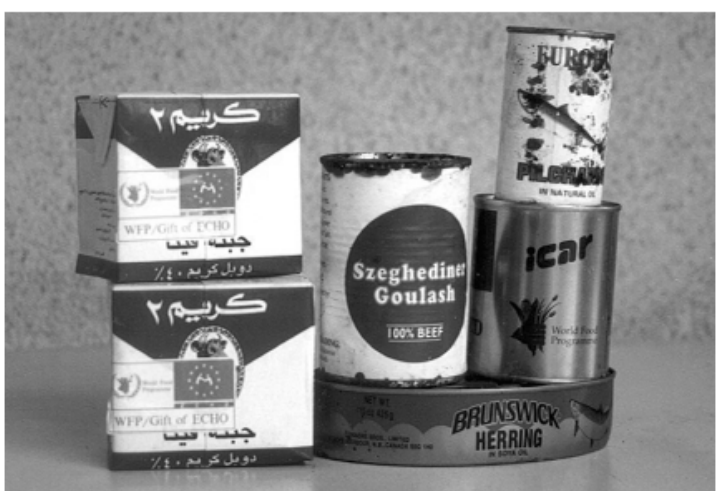

Fig. 6 Canned meat and different types of cheese donated over the course of the mentioned period.

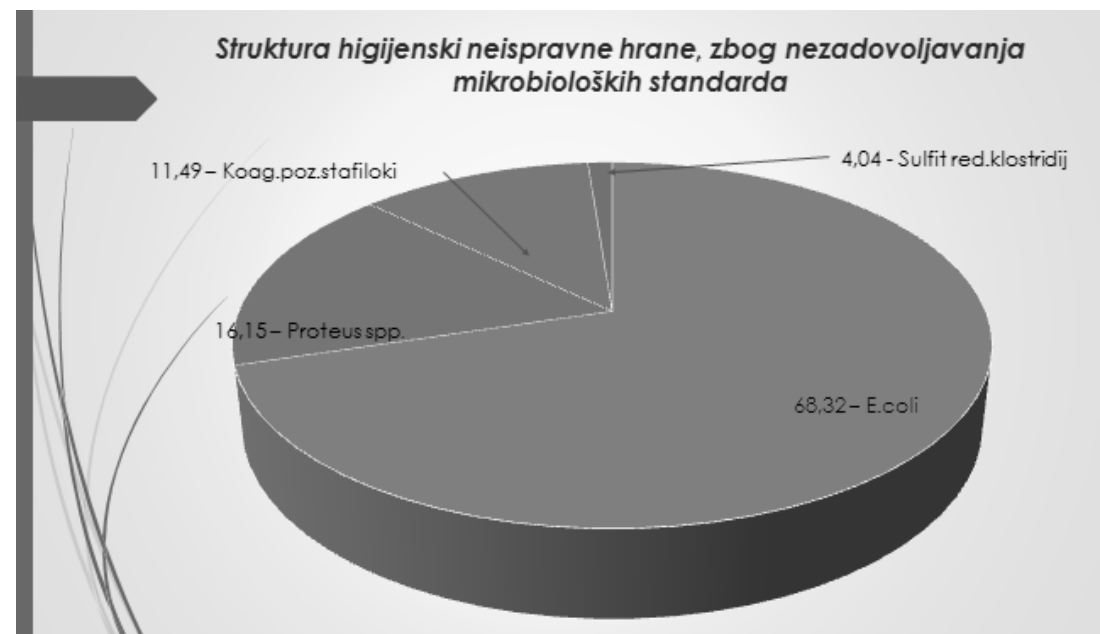

Fig. 7 Structure of foodstuffs failing to meet hygienicand microbiological standards. 


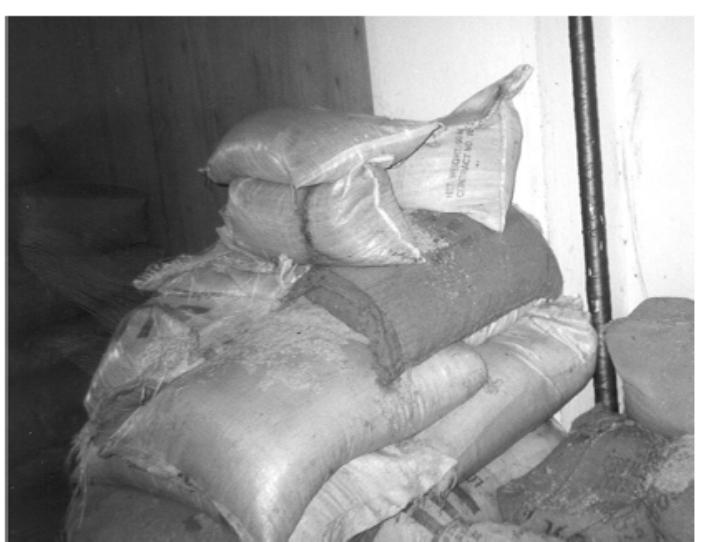

Fig. 8 Foodstuffs of plant origin donated over the course of the mentioned period.

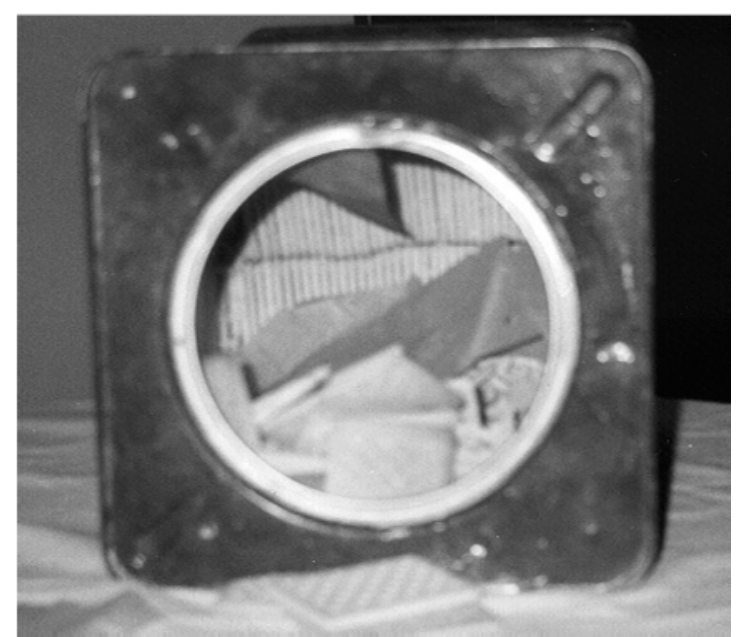

Fig. 9 Biscuits Handle with Care, produced during the 1957-1960 period. The UNICEF programme for nutrition of children and elederly people. Sarajevo, 1993.

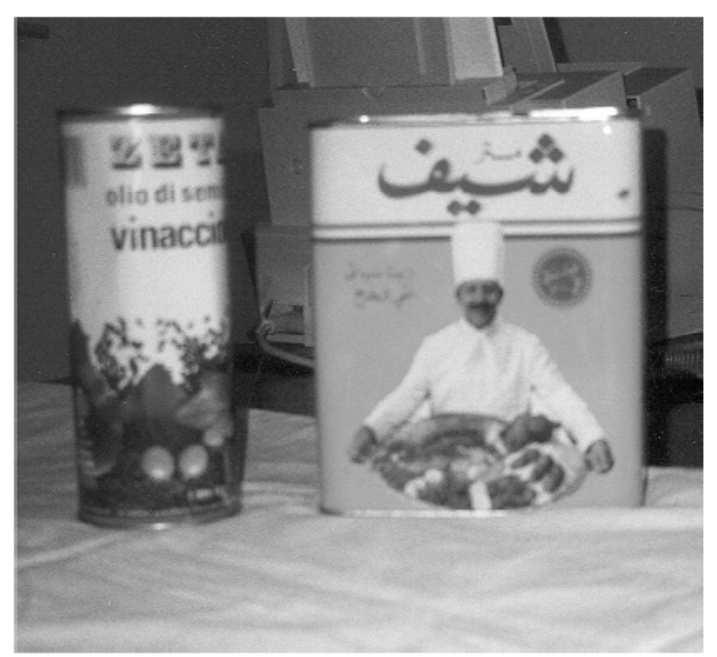

Fig. 10 Edible oil donation from Italy made of grape seed called "Zeta" and "Barbi" were hygienically suspicious according to the available literature.

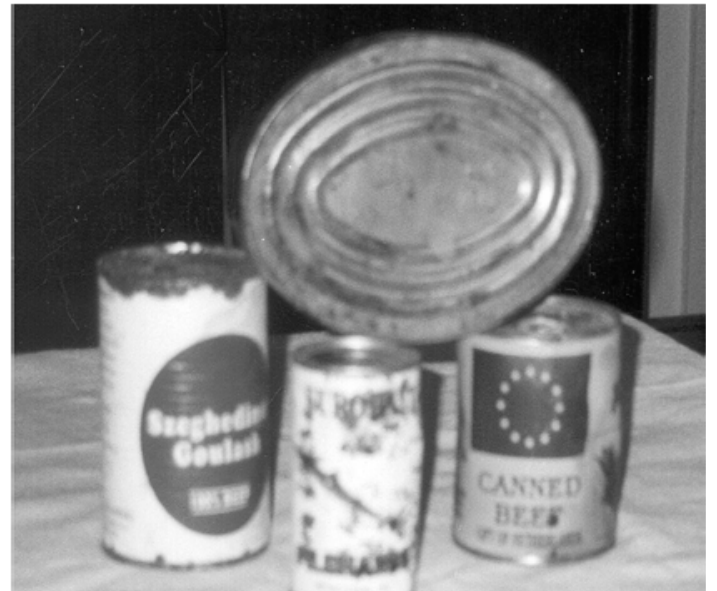

Fig. 11 Donated cans with visible corrosive processes and food items failing to meet health safety standards due to different reasons.

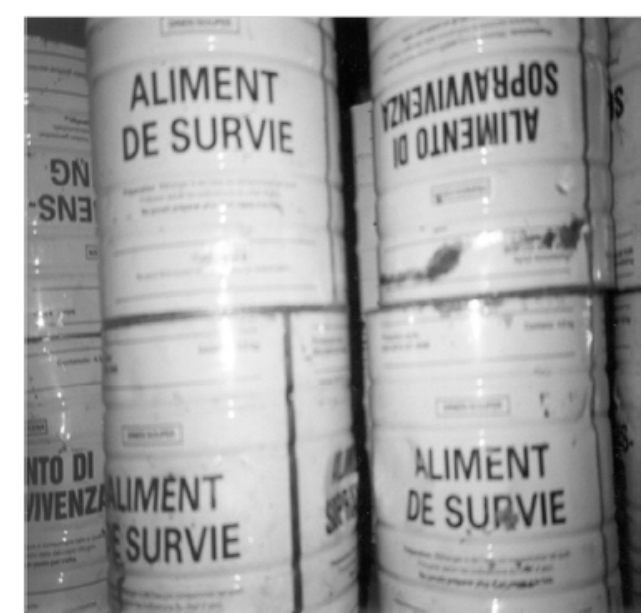

Fig. 12 Donated cans with visible corrosive processes and food items failing to meet health safety standards due to different reasons.

\subsection{Consequences of Poor Quality of Nutrition}

Because of poor nutrition, there was acute fatigue, sleepiness, grouchiness as well as negative implications on physical and mental condition, particularly among elderly people. There were cases of mental disorders, avitaminosis, anaemias, viraemias, etc. [4]. Poor nutrition had effect on the onset of TBC and increasing emergence of periodontal disease. The outcomes of treatment were less favourable among population with poor quality nutrition, which resulted, among other things, in a longer hospitalization time and a slower wound healing process (Figs. 13, 14). 


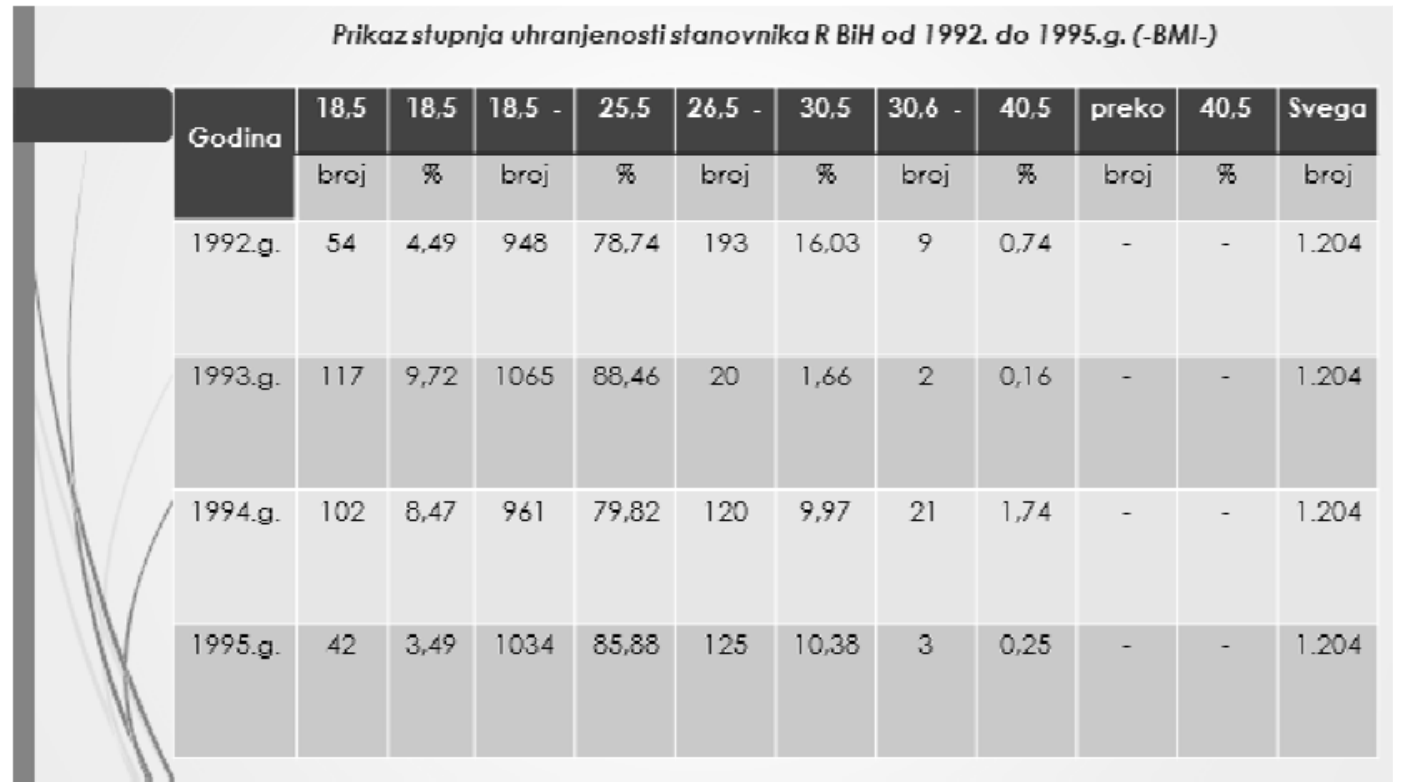

Fig. 13 Degree of nutritional status of the RBiH population 1992-1995 (BMI (Body Mass Index)).

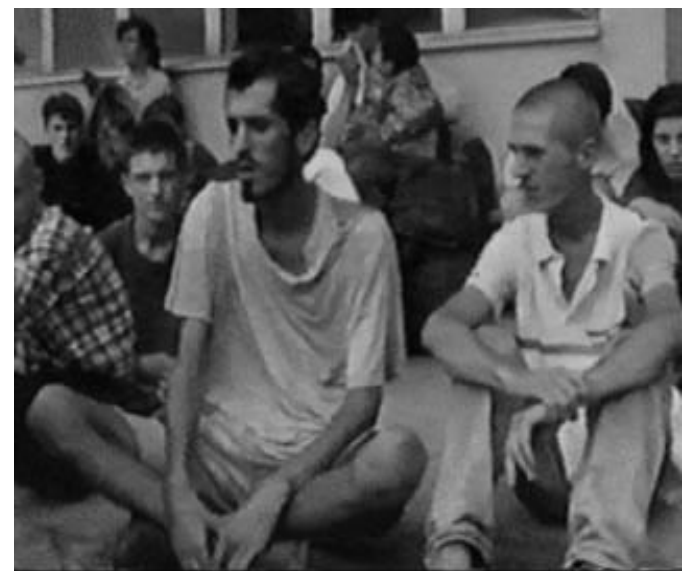

Fig. 14 Loss of body weight among population during the 1992-1995 period was up to $30 \mathrm{~kg}$.

\subsection{Consequences of Deficient Nutrition}

Other potential and expected consequences caused by insufficient and poor quality nutrition include: malnutrition, avitaminosis, dementia, alimentary intoxications, wild game meat poisoning, mushroom poisoning, hepatitis, problem with rehabilitation and wound healing, haemorrhagic fever, gastrointestinal tract illnesses and diseases of sociological nature such as high alcohol consumption, increased smoking, increased percentage of psychoneurosis and similar demand a fundamental clinical, laboratory, anthropometric, epidemiologic and other researches that may be the subject of the studies in the future period [5-7]. A comprehensive and professional effort and care for health that includes both physical and mental activity are most important in disease prevention. Dementia cannot be prevented, however, it is possible to reduce the risks of the diseases that cause dementia, primarily with proper lifestyle, proper nutrition, mental and social activities, physical activity and good sleep [8]. Power of quality stress management is an important factor in preventing the dementing conditions in population. It should be emphsized that prevention of demantia is an issue that even the latest studies have constantly raised andyet failed to provide a precise answer to this increasingly prevalent disorder [9].

\section{Conclusion}

There is potential for more substantial studies and examinations of how the inadequate quality and quantity of nutrition during the war, which can affect change and morphology of genetic code, affected the future generations because of cumulative effects of some of the contaminants in the food items. Two decades after the war, there have been increasing consequences among persons with dementia, 
especially as the result of poor quality of nutrition. It is therefore necessary to use multidisciplinary researches to verify the effects of inadequate nutrition on the development of dementia. It must be stated that some forms of dementia are hereditary while some are in correlation with a combination of genetic and environmental factors and lifestyle.

\section{Acknowledgement}

The research into the influence of diet on the symptoms of dementia among the citizens of $\mathrm{RBiH}$ during the period 1992-1995 showed that the food was of extremely poor quality and it evidently affected all health aspects of the citizens in the mentioned period. Symptoms of dementia are the ones that stood out in particular, with repercussions throughout later generations in the post-war period.

\section{References}

[1] Katica, A., Mlaćo, N., Hasanbašič, D., and Hamzić, E. 2010. Basic of Veterinary Histology. Sarajevo.

[2] Čaklovica, F., Milanović, A., Smajlović, M., Alić, B., and
Panić, L. 1995. "Hygienic Standards of Food and Quality of food and Hygienic Status of Food Manufacturing Plants in Sarajevo during 1992-1995 War." Veterinaria 41-44: 1-4.

[3] Kralj, I. 1993. "Energy Value and Biological Structure of Daily Meals During 1992-1993 War Perid.” Medical Bulletin 2: 1-5.

[4] Katica, V. 2001. Nutrition in War. PROMOCULT.

[5] William, C., and Shiel, J. 2016. "Dementio, Alzheimer's and Aging Brains." Accessed July 22, 2016. https://www.onhealth.com.

[6] Zec, S., Telebak, B., and Slijepčević, O. 1993. Nutrition under War Conditions. Symposium on War Medicine in War (92-93), Collection of Summaries. Sarajevo.

[7] Zec, S., and Telebak, B. 1993. Testing of Nutrition and Nutritional Status Under War Conditions, II Colloquium of Early and Late Health and Social Consequences Among Reugees and Displaced Persons. Sarajevo.

[8] The Centre for Dementia. 2015. "What is it and What next?" In Caregiver Guide. Sarajevo.

[9] Chen, H. 2013. "Features of Problematic Eating Behaviors among Community-Dwelling Older Adults with Dementia: Family Caregivers' Experience." Geriatric Nursing. 34 (5): 361-5. Accessed September-October 2013. https://www.alz.org/care/alzheimers-food-eating.asp\#nutr ition. 